\title{
Advanced Energy Storage Life and Health Prognostics (INL) FY 2012 Annual Progress Report
}

Jon P. Christophersen

Ira Bloom

Ed Thomas

Clair Ashton

David Robertson

John Morrison

William Morrison

Chinh Ho

October 2012

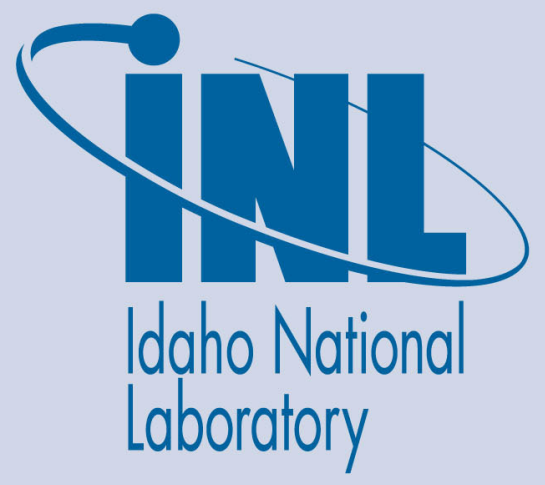

The INL is a U.S. Department of Energy National Laboratory operated by Battelle Energy Alliance 
INL/EXT-12-27612

\title{
Advanced Energy Storage Life and Health Prognostics
} (INL)

\section{FY 2012 Annual Progress Report}

\author{
Jon P. Christophersen \\ Ira Bloom ${ }^{1}$ \\ Ed Thomas ${ }^{2}$ \\ Clair Ashton \\ David Robertson ${ }^{1}$ \\ John Morrison ${ }^{3}$ \\ William Morrison ${ }^{4}$ \\ Chinh Ho \\ ${ }^{1} \mathrm{ANL}$ \\ ${ }^{2} \mathrm{SNL}$ \\ ${ }^{3}$ Montana Tech \\ ${ }^{4}$ University of Connecticut
}

October 2012

\section{Idaho National Laboratory Idaho Falls, Idaho 83415}

http://www.inl.gov

Prepared for the

U.S. Department of Energy

Assistant Secretary for Energy Efficiency and Renewable Energy

Under DOE Idaho Operations Office

Contract DE-AC07-05ID14517 


\section{III.D.2 Advanced Energy Storage Life and Health Prognostics (INL)}

Jon P. Christophersen, PhD
Idaho National Laboratory (INL)
P.O. Box 1625
Idaho Falls, ID 83415
Phone: (208) 526-4280; Fax: (208) 526-0690
E-mail: jon.christophersen@inl.gov
Collaborators:
Ira Bloom, ANL (BLE)
Ed Thomas, SNL (BLE)
Clair Ashton, INL (BLE)
David Robertson, ANL (BLE)
John Morrison, Montana Tech (ESMS)
William Morrison, University of Connecticut
(ESMS)
Chinh Ho, INL (ESMS)
Start Date: October 2008
Projected End Date: September 2013

\section{Objectives}

The objective of this work is to develop methodologies that will accurately estimate state-ofhealth (SOH) and remaining useful life (RUL) of electrochemical energy storage devices using both offline and online (i.e., in-situ) techniques through:

- A statistically robust offline battery calendar life estimator tool based on both testing and simulation, and

- $\quad$ Novel onboard sensor technology for improved online battery diagnostics and prognostics.

\section{Technical Barriers}

Presently, there are no adopted standards for assessing battery SOH and RUL and the U.S. automotive industry is confronted with the possibility of over-sizing batteries (thus increasing weight and cost) to minimize warranty claim issues and to ensure the required 15-year calendar life is met. Developing relevant approaches for both offline and online battery life and health prognostics addresses four primary technical barriers: cost, performance, abuse tolerance and reliability, and accurate life estimation. A successful SOH and RUL approach will enable OEMs to more smartly design battery packs with reduced weight and cost in addition to optimized power management for reduced range anxiety and improved performance. Battery safety could also be enhanced with improved online sensors that rapidly identify battery failure mechanism and help to prevent catastrophic events.

\section{Technical Targets}

- Update Battery Calendar Life Estimator Manual and software to include a non-linear model.

- Demonstrate the rate-based modeling approach for non-isothermal conditions using Sanyo SA cells.

- $\quad$ Validate rapid in-situ impedance spectrum measurement techniques for online life and health prognostic applications,

- $\quad$ Enhance rapid impedance spectrum measurement techniques based on feedback from OEMs. Particularly, in FY-12, focus on achieving faster impedance measurements at lower frequencies.

\section{Accomplishments}

- Revision 1 of the Battery Calendar Life Estimator Manual was completed and approved by the USABC TAC Test Methods Workgroup.

- Completed path dependence study with high power Sanyo SA cells.

- $\quad$ Initiated a new validation study using rapid impedance measurements at various depth-ofdischarge conditions.

- Developed a proof-of-concept for impedance measurements that are significantly faster than one period of the lowest frequency. Initial simulations indicate it may be possible to reduce a ten-second measurement down to 4.5 seconds.

\section{Introduction}

Robust, life estimation and onboard state-of-health assessment techniques remain a critical need for the successful and widespread implementation of battery technologies for various applications (automotive, military, space, telecommunications, etc.). Idaho, Argonne, and Sandia National Laboratories (INL, ANL and SNL, respectively) have collaborated on an offline battery life estimation tool for determining overall battery life expectancy under typical stress conditions (e.g., 15 year calendar life and 150,000 miles) with a 
high statistical confidence and within a short period of testing time. It is primarily intended to help manufacturers determine a technology's readiness for mass production and implementation.

The INL is also collaborating with Montana Tech of the University of Montana on developing an online (in-situ) sensor technology for rapid impedance measurements over a wide frequency range. Several techniques have been developed that can yield high resolution spectra within seconds. Information determined from onboard impedance measurements could then be combined with data from other sensors, models, and expert learning software to enable the development of an overall Energy Storage Monitoring System for advanced life and health prognostics that will be relevant to all industries that utilize expensive or mission-critical battery applications.

\section{Approach}

Battery Calendar Life Estimator. Revision 1 of the Battery Calendar Life Estimator (BCLE) Manual was completed in FY-12. This manual describes both a linearizable and non-linear model form for life assessment and provides a user's guide for the corresponding software tool. Additionally, the manual includes a section on rate-based modeling that is applicable for battery aging under non-isothermal conditions. To illustrate the rate-based approach, Sanyo SA cells were tested using the matrix shown in Table I. Cells were subjected to calendar-life tests at $60 \%$ state of charge (SOC) with reference performance tests (RPTs) every 32 days. Both INL and ANL had control groups at 45 and $55^{\circ} \mathrm{C}$ to establish the baseline performance at each temperature as well as to verify consistency between labs. The first non-isothermal group consisted of aging at $55^{\circ} \mathrm{C}$ until the power fade reached at least $15 \%$ and then switched to $45^{\circ} \mathrm{C}$ for the remainder of the calendar test (ANL performed the same test, but with the temperatures reversed). The other non-isothermal group consisted of switching between 55 and $45^{\circ} \mathrm{C}$ during aging after each RPT.

Novel Online Sensor Technology. Initial validation and demonstration of the rapid impedance measurement technique known as Harmonic Compensated Synchronous Detection (HCSD) has been previously completed. In FY-12, an additional study was initiated to explore the differences in impedance spectra as a function of state-of-charge and aging. Nine Sanyo SA cells are being calendar-life aged at $50^{\circ} \mathrm{C}$ with RPTs every 32.5 days. One group of three cells is subjected to a standard pulse-per-day test followed by a voltage clamp at $60 \%$ SOC; a second group of three cells is also voltage clamped at $60 \%$ SOC with an HCSD measurement once per day; the third group is simply clamped at $60 \%$ SOC without any daily measurements. The RPTs consist of a standard lowcurrent Hybrid Pulse Power Characterization (L-HPPC) with a ten-second HCSD impedance measurement immediately prior to the pulse profile at each $10 \%$ depth-of-discharge (DOD) increment.

Table I: Sanyo SA cell test matrix for memory study

\begin{tabular}{|c|c|c|c|c|c|}
\hline Lab & $\begin{array}{c}\text { Group } \\
\# \\
\end{array}$ & Type & Label & Cells & $\begin{array}{c}\text { Temp. } \\
\left({ }^{\circ} \mathrm{C}\right) \\
\end{array}$ \\
\hline \multirow{4}{*}{ INL } & 1 & ISO-LO & Control & 3 & 45 \\
\hline & 2 & ISO-HI & Control & 3 & 55 \\
\hline & 3 & $\begin{array}{l}\text { NON- } \\
\text { ISO }\end{array}$ & Switch & 3 & $55 \rightarrow 45$ \\
\hline & 4 & $\begin{array}{c}\text { NON- } \\
\text { ISO }\end{array}$ & Pulse & 3 & $55 / 45$ \\
\hline \multirow{4}{*}{ ANL } & 5 & ISO-LO & Control & 3 & 45 \\
\hline & 6 & ISO-HI & Control & 3 & 55 \\
\hline & 7 & $\begin{array}{l}\text { NON- } \\
\text { ISO }\end{array}$ & Switch & 3 & $45 \rightarrow 55$ \\
\hline & 8 & $\begin{array}{c}\text { NON- } \\
\text { ISO }\end{array}$ & Pulse & 3 & $45 / 55$ \\
\hline
\end{tabular}

\section{Results}

Battery Calendar Life Estimator. Most of the Sanyo SA cells have completed ten RPTs. The "Pulse" groups (i.e., " $55 / 45$ " and " $45 / 55$ ") began testing a month later and are one RPT behind. The INL "Switch" group that was initially aged at $55^{\circ} \mathrm{C}$ surpassed $15 \%$ power fade after RPT3 and was then aged at $45^{\circ} \mathrm{C}$ through RPT10. Likewise, the corresponding ANL group switched from 45 to $55^{\circ} \mathrm{C}$ after the RPT6. Figure I shows the average available power at $500 \mathrm{Wh}$ for each cell group based on the PHEV targets. The ANL cells show a larger initial power capability (approximately $65 \mathrm{~kW}$ at RPT0 compared to $58 \mathrm{~kW}$ for the INL cells) and the rate of degradation through ten months of calendar aging appears to be slightly higher for the INL cells.

However, the results seem to be internally consistent within each laboratory, which indicates the presence of cell manufacturing variability. Table II shows the average capacity and power fade for each cell group through RPT10 (the "Pulse" groups are shown in italics since they are the average fade results through RPT9). Both the capacity and power fades are generally similar for each group and the "Switch" cells that started at $55^{\circ} \mathrm{C}$ show more fade than the corresponding cells that started at $45^{\circ} \mathrm{C}$, as expected. These data indicate that there is not a significant presence of memory effects or path dependence for this given temperature range. 


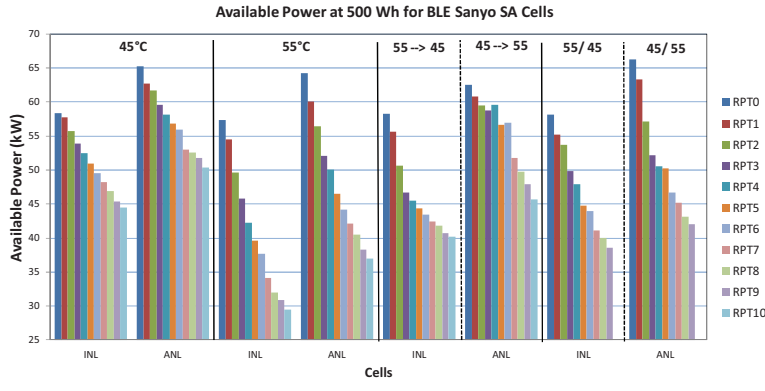

Figure I: Average power fade for BLE Sanyo cells.

Table II: Sanyo SA cell test matrix for memory study

\begin{tabular}{ccccc}
\hline \hline Lab & Group \# & $\begin{array}{c}\text { Temp. } \\
\left({ }^{\circ} \mathbf{C}\right)\end{array}$ & $\begin{array}{c}\text { Capacity } \\
\text { Fade (\%) }\end{array}$ & $\begin{array}{c}\text { Power } \\
\text { Fade (\%) }\end{array}$ \\
\hline \hline & 1 & 45 & $25.28 \%$ & $23.81 \%$ \\
INL & 2 & 55 & $46.18 \%$ & $48.62 \%$ \\
& 3 & $55 \rightarrow 45$ & $34.18 \%$ & $31.02 \%$ \\
& 4 & $55 / 45$ & $35.11 \%$ & $33.71 \%$ \\
\hline- & 5 & 45 & $21.95 \%$ & $22.90 \%$ \\
& 6 & 55 & $38.96 \%$ & $42.46 \%$ \\
ANL & 7 & $45 \rightarrow 55$ & $25.87 \%$ & $26.58 \%$ \\
& 8 & $45 / 55$ & $33.11 \%$ & $36.53 \%$ \\
\hline \hline
\end{tabular}

Rate-based modeling is an approach for battery life estimation using instantaneous degradation rates instead of cumulative degradation over a given time. The advantage of rate-based modeling is that it can be applied to non-isothermal aging conditions which are more realistic in automotive (and other) environments. The generalized model form was provided in the Revision 1 of the BCLE Manual and successfully illustrated using the Sanyo SA cells. Figure II shows the relative resistance growth as a function of test time for the INL cell groups along with the corresponding rate-based model fit. Although there is some evidence of lack-of-fit, the model does a good job of fitting all of the test conditions even with the variations in temperature. The 2010 hourly ambient temperature profile from Phoenix, AZ, shown in Figure III, was used over repeated instances to estimate the overall life capability of these cells under non-isothermal conditions. From the BCLE simulations, the mean cell life (i.e., when the relative resistance first exceeds 1.3) is 4.5 years with a $95 \%$ upper and lower confidence bound of 4.75 and 3.7 years, respectively.

Novel Online Sensor Technology. The Sanyo cells used in this study have completed RPT6. Table III shows the average capacity and power fade for each cell group. The results are similar for all three groups, indicating that there is not a significant difference between a pulse-per-day, and HCSD-per-day, or simply clamping the OCV at the target SOC. Figure IV shows the ten-second impedance spectra captured at each 10\% DOD increment for a representative cell at both beginning of life and after RPT5. The RPT5 spectra were artificially shifted to the right by $12 \mathrm{~m} \Omega$ for better qualitative comparisons. Unfortunately, most of the RPT6 data were corrupted from noisy measurements which may have been caused by the mechanical relays wearing out. The spectra clearly show that, at a given point in life, there is negligible change in the ohmic resistance (i.e., the point at which the spectra crosses the real axis), but the mid-frequency charge transfer resistance increases in both height and width with increasing DOD. Additionally, the mid-frequency semicircle grows as a function of aging as well, which is consistent with previous validation testing results.

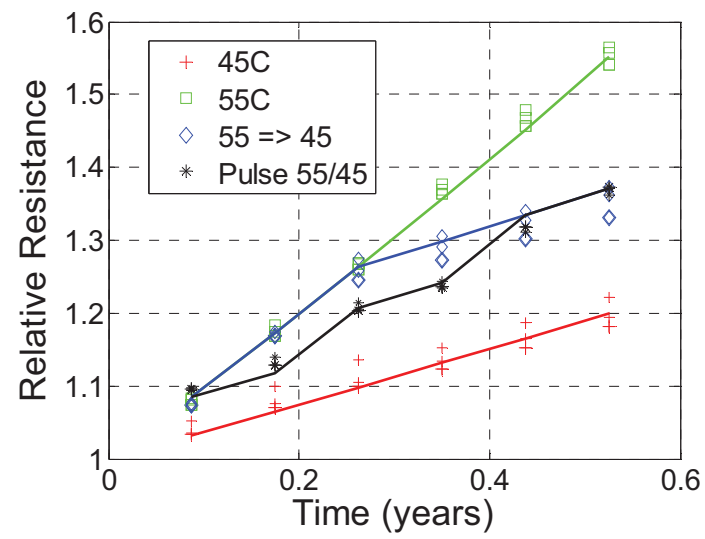

Figure II: Generalized rate-based model fit of relative resistance using INL cell groups.

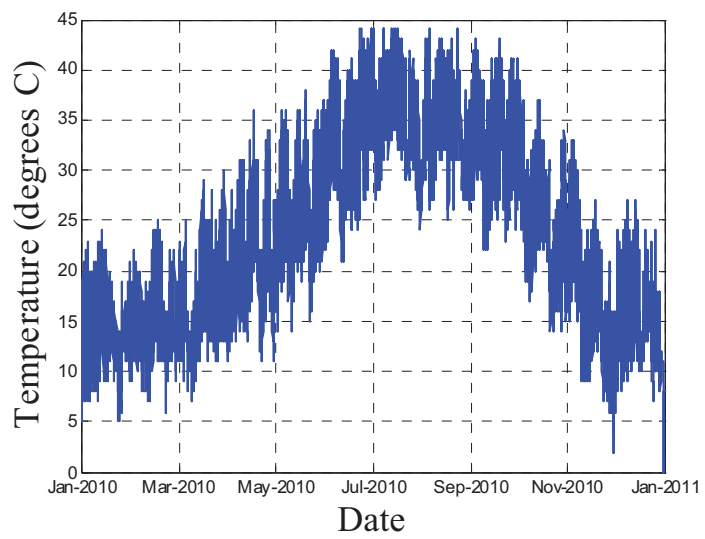

Figure III: Hourly temperature profile for Phoenix, AZ (2010).

Table III: Sanyo SA cell performance for HCSD study

\begin{tabular}{ccc}
\hline \hline \multirow{2}{*}{ RPT6 } & $\begin{array}{c}\text { Capacity } \\
\text { Fade (\%) }\end{array}$ & $\begin{array}{c}\text { Power } \\
\text { Fade (\%) }\end{array}$ \\
\hline \hline Pulse-per-Day & $25.24 \%$ & $23.55 \%$ \\
OCV Clamp & $24.42 \%$ & $25.10 \%$ \\
HCSD-per-Day & $23.56 \%$ & $23.15 \%$ \\
\hline \hline
\end{tabular}




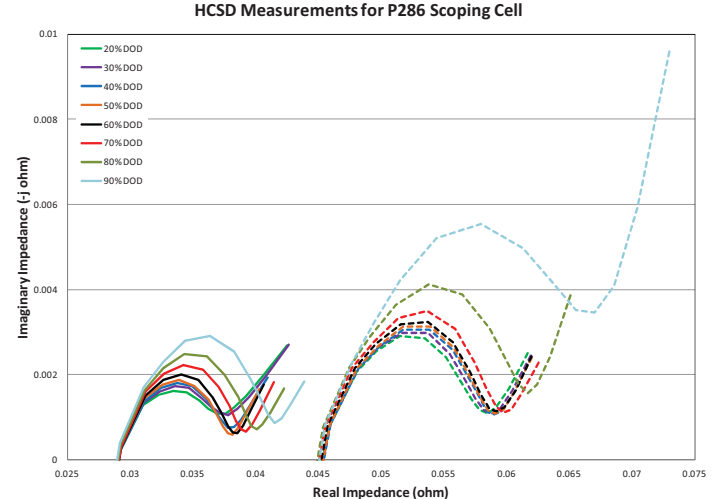

Figure IV: HCSD vs. DOD at RPT0.

Figure $\mathrm{V}$ shows the measured impedance spectra at $40 \%$ DOD for the same representative cell between RPT0 and RPT6. As observed above, the majority of the impedance growth as a function of aging occurs at the mid-frequency region, but there is evidence of some growth in the ohmic resistance as well. This is also consistent with previous validation testing results. Similar results were also observed for the other DOD conditions as a function of cell age. These data indicate that HCSD impedance spectra could be useful for rapid, onboard detection of state-of-charge. Developing such a prognostic tool is anticipated future work for FY-13.

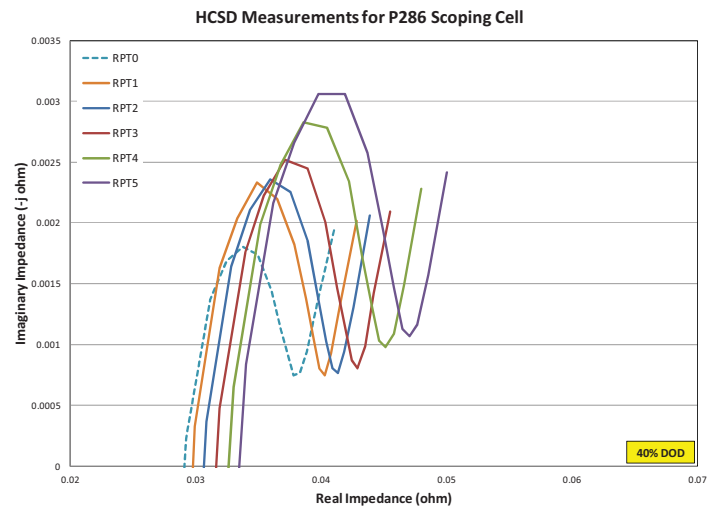

Figure V: HCSD vs. RPT at 40\% DOD.

\section{Conclusions and Future Directions}

The objective of the Battery Calendar Life Estimation manual is to develop a statistically robust offline life estimation tool that incorporates both standardized aging protocols and various off-normal degradation effects. Of particular interest is the memory effect when aging over different temperatures. A path dependence study was completed in FY-12 and the results were incorporated into Revision 1 of the manual.

The objective of the novel online sensor technology development is to enable rapid, onboard impedance spectra measurements for improved battery life and health prognostics. The HCSD vs. SOC validation study in FY-12 has shown that the impedance spectra change as a function of increasing DOD and age. Additionally, the change in impedance spectra appears to be consistent and repeatable, which further indicates that it is possible to detect SOC from a rapid impedance measurement. Mapping the relationship between SOC and impedance is anticipated work for FY-13. Also, it is anticipated that validation studies will continue in FY-13 with a specific focus on under load measurement conditions as well as string dynamic studies based on interconnected cell testing.

\section{FY 2012 Publications/Presentations}

1. Battery Calendar Life Estimator Manual, Revision 1, INL/EXT-08-015136, October 2012.

2. E. V. Thomas, I. Bloom, J. P. Christophersen, and V. S. Battaglia, "Rate-based modeling of lithium-ion cells," J. Power Sources, 206, 378-382 (2012).

3. J. P. Christophersen, Developing Modeling Capability to Predict Battery Life, invited presentation for the 2012 Prognostics and System Health Management Conference, Beijing, China, May 2012.

4. J. Christophersen, J. Morrison, W. Morrison, C. Motloch. Rapid Impedance Spectrum Measurements for State-of-Health Assessment of Energy Storage Devices, SAE Int. J. Passeng. Cars - Electron. Electr. Syst. 5(1), 2012.

5. J. Christophersen, J. Morrison, D. Rose, W. Morrison, C. Motloch. Crosstalk Compensation for a Rapid, Higher-Resolution Impedance Spectrum Measurement, IEEE Aerospace Conference Proceedings, 2012.

6. W. Morrison, J. Morrison, J. Christophersen, P. Bald. An Advanced Calibration Procedure for Complex Impedance Spectrum Measurements of Advanced Energy Storage Devices. 58th International Instrumentation Symposium Proceedings, 2012.

7. P. A. Bald, E. Juras, J. P. Christophersen, W. H. Morrison, J. L. Morrison, Hardware Architecture for Rapid Impedance Measurements of $50 \mathrm{~V}$ Battery Modules. 58th International Instrumentation Symposium Proceedings, 2012.

8. J. P. Christophersen, C. D. Ho, J. L. Morrison, Rapid Impedance Spectrum Measurement for Onboard State-of-Health Applications. 45th Power Sources Conference Proceedings, 2012.

9. H. E. Garcia, A. Mohanty, J. P. Christophersen, W. Lin, On-line State-of-Health and Remaining-UsefulLife Assessment of Batteries using Rapid Impedance Spectrum Measurements. 45th Power Sources Conference Proceedings, 2012. 